\title{
Evaluating of Phage as Bio-control Agent in Enumeration of Food Borne Pathogenic Pseudomonas aeruginosa
}

\author{
V.B. Hemalata ${ }^{1}$, Ajay Kumar $\mathrm{Oli}^{2}\left(\mathbb{D}\right.$ and D.B.M. Virupakshaiah ${ }^{3 *}$ (1) \\ ${ }^{1}$ Department of Biotechnology, Basaveshwar Engineering College, Bagalkot - 587 103, Karnataka-India. \\ ${ }^{2}$ Department of Basic Science, SDM Research Institute for Biomedical Sciences, Dharwad - 580009 Karnataka, \\ India. ${ }^{3}$ Department of Microbiology, Davangere University, Davangere - 577007 Karnataka, India.
}

\begin{abstract}
Phage acts as a bio-controlling agent to overcome chemical supplement in the treatment food pathogens. Bacterial pathogens mainly cause food borne diseases; these are harmful to human health and also threat to nutritional economy. Due to aggregating in the multidrug resistance among the pathogens, the conventional methods for food safety are drawn in the use of chemicals and causes toxicity. In our present study, the $P$. aeruginosa isolates were determined from food samples on specific Cetrimide agar and a specific phage was isolated against the strain. The microbial enumeration growth was carried out on meat samples. The preservative activity was performed on banana samples. The present phage has indicated a prominent agent in enumeration of microbial growth against meat and mutton samples. It also showed a quality preservative for storage in banana samples. The potential advantage of using phage is their specificity and ability to multiply; hence, it can be used in food safety and provide a natural alternative to conventional synthetic preservatives used in food industries. The phage has ability in decreasing the growth microbes in food samples and long storage as preservative in fruits.
\end{abstract}

Keywords: Bacteriophages, Biocontrol, Preservatives, Pseudomonas aeruginosa, Food safety

(C) The Author(s) 2020. Open Access. This article is distributed under the terms of the Creative Commons Attribution 4.0 International License which permits unrestricted use, sharing, distribution, and reproduction in any medium, provided you give appropriate credit to the original author(s) and the source, provide a link to the Creative Commons license, and indicate if changes were made. 


\section{INTRODUCTION}

Food safety is an individual concerns because of threatening human health caused by variety of foodborne pathogens. In general, these foodborne pathogens can be prevented by using chemical and natural food preservative (Jaewoo et al., 2016). Consumers distaste the use of chemical preservatives in their food, as they have been associated with public health risk alarm. The scenarios increase the anxiety that chemically synthesized substance should be separated from the food and accept the "natural" means of preservatives. Since there are different ways of using natural preservatives, the utmost approach widely acceptable to use bio-control agents (McIntryre et al., 2007, Kalkan et al., 2011).

Pseudomonas species inhabit a wide variety of biological niches because they quickly acclimatize for diverse environmental conditions. The main sources of Pseudomonas species are soil and water whereas, $P$. aeruginosa, $P$. plecoglossicida are present in the animals and $P$. syringae species represent in the plants. The significant appliance of antibiotic forced on multidrug resistant bacteria, especially Pseudomonas. Consequently, pathogenic bacteria have become into obstinate entity. P. aeruginosa is one of the most pathogen in contamination in mutton and chicken samples. The prevalence of food contamination in the food stalls is due to lack of knowledge at one hand and nut negligence of food handlers is on other hand. (Ankita et al., 2012).

Bio-control agents are the biological factors which are used against different pathogens and saprophyte. Twort 1915 and d'Herelle 1917 have discovered the bacteriophage and proposed these can be used as bio-control agent. Unfortunately, today the studies and application of bacteriophage revived due increase in antibiotic resistance and can be an alternative as a biocontrol factor as a phage therapy (Hagens et al., 2007).

Bacteriophages are present as biological entities in nature and is predicated as potential therapeutic agents. In modern years overprescription of antibiotic are associated in the development of drug resistance known to be 'super-bugs' have decorated the need for alternative approaches to combat infectious diseases (Brussow et al., 2002). Subsequently, a lot of research undergone from past two decades on phages and it was aimed phage can be used to eliminate undesirable bacteria. Phages are omni present and are habitually consumed through absorption of water and food (Esteban et al., 2008). Due to current purpose, they are presumed to be safe and its adverse effects have not yet been reported. Due to its inherent specific property the phages are used as an excellent tool for food safety functions. (Healy et al., 2010; Mahony et al., 2011).

Overview of bacteriophages acts on pathogenic without affecting beneficial bacteria and host organism. It has especially showed efficacy against Pseudomonas species (Jaewoo et al., 2016). Phages are used against disease causing $P$. aeruginosa, and it can be powerful tool in eliminating the infection. The use of phage or phage products is a novel method implemented in food production and it is an option for the food industry as biological controlling agent or to remove the unwanted pathogens, enhancing the safety of especially fresh food products (Novik et al., 2015).

In the middle of the $20^{\text {th }}$ century, the first reported on isolation of bacteriophages against for the specific Pseudomonas genus and currently there are 137 completely sequenced Pseudomonas phage genomes are available in the biological databases. P. aeruginosa is an opportunistic, hospital-acquired and well as foodborne pathogenic, large fractions of the phage application revisions and genome sequencing projects have been focused on the bacterium (Diana et al., 2015). Many Pseudomonas phages are belong to the order Caudovirales with three prominent families (Ceyssens et al., 2010). Lytic phages are mainly categorized in Myoviridae family with a long contractile tail, and the Podoviride carries a short tail, temperate phage belong to Siphoviridae, indicating the possibility to undergo lytic or lysogenic interactions with their host (Latino et al., 2014).

Therefore, general features and various food applications of phages for biocontrol of foodborne pathogens would be the using specific virulent bacteriophages for $P$. aeruginosa to reduce the bacterial load in foods of animal origin and plant origin emerges as alternative method. 


\section{MATERIALS AND METHODS Collection of Meat samples}

Fresh sliced meat samples (chicken and mutton) were collected from local market in and around Bagalkot district, Karnataka, India. Each sample was wrapped separately in sterile polyethylene bags, transferred into the ice box, and transported as quickly as possible to the laboratory.

\section{Culture preparation}

Pseudomonas aeruginosa strains were isolated from food samples in the Department of Biotechnology, Basaveshwar Engineering College, Bagalkot. Strains were isolated in cetrimide specific agar media and incubated for 24 hours at $37^{\circ} \mathrm{C}$, to determine cell concentration. Inoculum size used for experimental were $\sim 10^{2}$ to $10^{5} \mathrm{CFU} / \mathrm{g}$.

\section{Preparation of Bacteriophages}

Pseudomonas specific bacteriophage was isolated from standard enrichment procedure; raw sewage sample was collected from a municipal sewage treatment system. Pseudomonas Strains were inoculated $1: 100$ in $200 \mathrm{ml}$ of $\mathrm{BHI}$ and kept in incubator shaker at $37^{\circ} \mathrm{C}$ for $240 \mathrm{rpm}$. When an $O D$ reaches 0.1 measured at $600 \mathrm{~nm}$; stock phages were inoculated with $10^{7}$ plaque forming unit (PFU/g).

\section{Application of bio-control agent for sliced meat} samples (chicken and mutton)

Sliced meat samples were inoculated by the activated selected culture of Pseudomonas aeruginosa $\left(10^{5} \mathrm{CFU} / \mathrm{g}\right)$ and Bacteriophage treated in $\left(10^{7} \mathrm{PFU} / \mathrm{g}\right)$ and divided into four equal portions/ groups, respectively. Un-inoculated meat sample served as control (untreated). Each treatment was packed in sterile aluminum foil and incubated in different conditions; $37^{\circ} \mathrm{C}, 15-18^{\circ} \mathrm{C}, 4^{\circ} \mathrm{C}$ and $-20^{\circ} \mathrm{C}$ and then were examined by microbiologically.

\section{Physiological / Morphological characterization}

Sliced meat samples were observed for changes like texture, odour and colour changes; were observed during incubation and recorded.

\section{Microbiological analyses}

Sliced meat samples were thoroughly homogenized in $0.9 \%$ saline and serially diluted up to ratio of $10^{7}$. The sample was inoculated in agar plates with homogenate by spreading $0.1 \mathrm{ml}$ on each plate with sterile bent glass. Plates were incubated for $18-24 \mathrm{hrs}$ at $37^{\circ} \mathrm{C}$.
Bio-control agent for food born Pseudomonas aeruginosa using Banana

Materials

Fresh raw bananas were collected from local field in and around Bagalkot district, Karnataka, India. The collected sample was transferred into sterile polyethylene bags and transported to the laboratory.

\section{Preparation of solution}

i) Solution of Sodium alginate $(3 \%, w / v)$, ii) Starch solution $(4 \%, w / v)$, iii) Gelatin solution $(3 \%, w / v)$ were primed by addition of required salt concentration and followed by heating at $90^{\circ} \mathrm{C}$, stirred until the salt complete dissolves, iv) Glycerol solution $(3 \%, \mathrm{w} / \mathrm{v})$ was prepared by addition glycerol in distilled water and autoclaved. v) Fresh Aloe gel (AG; 100\%). The gel was sterilized at $70^{\circ} \mathrm{C}$ for $45 \mathrm{~min}$. Then the gel was immediately cooled at room temperature. To facilitate coating the gel was thickened using $1 \%$ gelling agent. The prepared gel finally applied to coat fresh fruits with brushing.

\section{Sample Preparation}

The bananas without any signs of fungal decay or any mechanical damage were selected and pre-sterilized with sodium hydrochloride solution by incubating for $4 \mathrm{~min}$, and then dried by natural convection at $25^{\circ} \mathrm{C}$ prior to coat. The coating process was carried out with brushing, and application of following solution, Sodium alginate, Starch, Gelatin, Glycerol and Aloe vera gel matrixes. Coated fruits were dried in a clean tray with placing sterile filter paper on the tray and stored at room temperature at dried place for 21 days.

Physiological / Morphological characterization Bananas were observed for morphological

Table 1. A. Showing physiological and morphological characterization of sliced meat sample

\begin{tabular}{llll}
\hline Days & Texture & Odour & Colour \\
\hline 0 day & Fresh & Light/fresh & Bright red \\
1 day & Slimy & Sour & Red \\
2 day & Sticky & Rotten egg(slightly) & Brown \\
3 day & Sticky & Rotten egg & Dark grey \\
4 day & Sticky & Very bad (stinky & Black \\
& & rotten egg/ & \\
& & ammonia) & \\
\hline
\end{tabular}


changes like texture; odour and colour changes were observed during incubation and recorded.

\section{RESULTS}

Bio-control agent for food born Pseudomonas aeruginosa using sliced meat sample Preparation of Bacteriophages

Pseudomonas specific bacteriophage was used as per the meat sample weight and based on that required doses were used for the application of meat samples.

\section{Physiological / Morphological characterization}

Sliced meat samples were observed for changes like texture, odour and colour changes in different conditions $37^{\circ} \mathrm{C}, 15-18^{\circ} \mathrm{C}, 4^{\circ} \mathrm{C}$ and $-20^{\circ} \mathrm{C}$ for 4 days and each day changes were observed and recorded in Table 1 and morphological changes visualized and analyzed with proper parameter of treated sample. In the initial day of incubation, the sample resembles a fresh as shown in the Fig. 1.A.

On $4^{\text {th }}$ day of period, the sample looks completely spoiled both control and Pseudomonas treated samples whereas bacteriophage treated sample look like slightly spoiled as Fig. 1.B. In Fig. 1.C, the mutton meat samples are fresh and no sign of spoilage at first day of incubation and Fig. 1.D, indicate the $4^{\text {th }}$ day of incubation and looks like completely spoiled (sticky) both control and Pseudomonas treated samples whereas bacteriophage treated sample appearance similar slightly sour. All the meat samples were observed

Table 1.B. Showing number colony count after treated with bacteriophage against $P$. aeruginosa Strain on chicken samples on a completion of 4 th incubation at various temperatures

\begin{tabular}{|c|c|c|c|c|c|c|c|c|c|c|c|c|c|c|c|}
\hline \multirow[t]{2}{*}{ SI. No } & \multicolumn{3}{|c|}{$\begin{array}{c}\text { Initial day of } \\
\text { count }\end{array}$} & \multicolumn{3}{|c|}{$\begin{array}{l}\text { Incubation on } \\
4^{\text {th }} \text { day at } 37^{\circ} \mathrm{C}\end{array}$} & \multicolumn{3}{|c|}{$\begin{array}{l}\text { Incubation on } \\
4^{\text {th }} \text { day at } 15-30^{\circ} \mathrm{C}\end{array}$} & \multicolumn{3}{|c|}{$\begin{array}{l}\text { Incubation on } \\
4^{\text {th }} \text { day at } 4^{\circ} \mathrm{C}\end{array}$} & \multicolumn{3}{|c|}{$\begin{array}{l}\text { Incubation on } \\
4^{\text {th }} \text { day at }-20^{\circ} \mathrm{C}\end{array}$} \\
\hline & $10^{3}$ & $10^{4}$ & $10^{5}$ & $10^{3}$ & $10^{4}$ & $10^{5}$ & $10^{3}$ & $10^{4}$ & $10^{5}$ & $10^{3}$ & $10^{4}$ & $10^{5}$ & $10^{3}$ & $10^{4}$ & $10^{5}$ \\
\hline Control & 188 & 139 & 69 & 3198 & 3313 & 1097 & 925 & 876 & 801 & 525 & 487 & 446 & 350 & 258 & 185 \\
\hline P. aeruginosa & 197 & 155 & 75 & 3982 & 3115 & 3076 & 860 & 793 & 582 & 610 & 579 & 515 & 345 & 298 & 210 \\
\hline $\begin{array}{l}\text { PA Strain } \\
\text { and Phage }\end{array}$ & 182 & 137 & 67 & 1912 & 1097 & 1003 & 643 & 573 & 519 & 503 & 423 & 403 & 295 & 216 & 158 \\
\hline
\end{tabular}

Table.1.C. Showing number colony count after treated with bacteriophage against $P$. aeruginosa Strain on mutton samples on at completion of 4 th incubation at various temperatures

\begin{tabular}{|c|c|c|c|c|c|c|c|c|c|c|c|c|c|c|c|}
\hline \multirow[t]{2}{*}{ SI. No } & \multicolumn{3}{|c|}{$\begin{array}{c}\text { Initial day of } \\
\text { count }\end{array}$} & \multicolumn{3}{|c|}{$\begin{array}{l}\text { Incubation on } \\
4^{\text {th }} \text { day at } 37^{\circ} \mathrm{C}\end{array}$} & \multicolumn{3}{|c|}{$\begin{array}{l}\text { Incubation on } \\
4^{\text {th }} \text { day at } 15-30^{\circ} \mathrm{C}\end{array}$} & \multicolumn{3}{|c|}{$\begin{array}{l}\text { Incubation on } \\
4^{\text {th }} \text { day at } 4^{\circ} \mathrm{C}\end{array}$} & \multicolumn{3}{|c|}{$\begin{array}{l}\text { Incubation on } \\
4^{\text {th }} \text { day at }-20^{\circ} \mathrm{C}\end{array}$} \\
\hline & $10^{3}$ & $10^{4}$ & $10^{5}$ & $10^{3}$ & $10^{4}$ & $10^{5}$ & $10^{3}$ & $10^{4}$ & $10^{5}$ & $10^{3}$ & $10^{4}$ & $10^{5}$ & $10^{3}$ & $10^{4}$ & $10^{5}$ \\
\hline Control & 375 & 308 & 291 & 5147 & 5085 & 4896 & 2298 & 2207 & 2099 & 1458 & 1301 & 1198 & 787 & 717 & 685 \\
\hline P. aeruginosa & 427 & 398 & 369 & 5098 & 4982 & 4736 & 2400 & 2320 & 2218 & 1650 & 1523 & 1399 & 800 & 735 & 670 \\
\hline $\begin{array}{l}\text { PA Strain } \\
\text { and Phage }\end{array}$ & 418 & 389 & 353 & 2115 & 2003 & 1193 & 2169 & 2100 & 1995 & 1387 & 1276 & 1160 & 550 & 510 & 465 \\
\hline
\end{tabular}

Table 1. D. Showing physiological and morphological characterization of banana sample

\begin{tabular}{lllll}
\hline Days & Appearance/ Colour & Texture & Odour & Taste \\
\hline 0 day & Greenish & Hard to break & No smell & Starchy \\
5 day & Yellow & Too firm/not soft & No smell & Chalky \\
9 day & Brown spots & Soft but firm & Sweet/pleasant & Nice \& sweet \\
14 day & Lots of brown spots & Soft but firm & Appealing & Easy to chew \\
19 day & Any green or yellow areas & Yields to pressure & No smell & Starchy \\
21 day & Completely black & Mushier the better & Sweet/pleasant/ & delicious \\
& & & appealing & \\
\hline
\end{tabular}


for their texture, odour and colour change at completion of four days and recorded.

\section{Physiological / Morphological changes in meat} sample

\section{Microbiological analyses}

Sliced meat samples were subjected for the microbiological analyses by SPC (Standard Plate Count); in the present study the control chicken sample showed $1.8 \times 10^{5}, 0.139 \times 10^{6}$ and $0.69 \times 10^{7}$ microbial growth, respectively. The treated sample showed increase microbial population as $1.97 \times 10^{5}, 1.55 \times 10^{6}, 0.75 \times 10^{7}$, and treated with phage as showed in the decrease in the growth of microbial $1.82 \times 10^{5}, 1.37 \times 10^{6}$, and $0.67 \times 10^{7}$ respectively as demonstrated in the Table 1.B and Fig. 2.1 initial day of incubation.

The development of microbial population on fourth day of incubation at $37^{\circ} \mathrm{C}$ as indicated
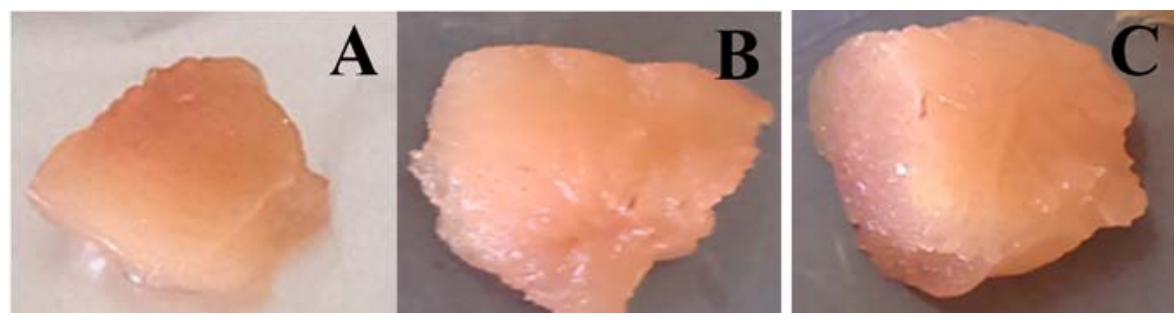

Fig. 1. A.
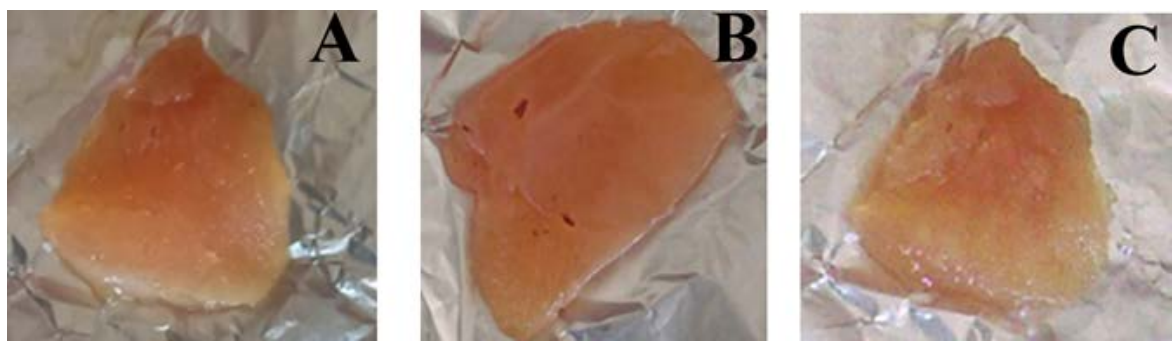

Fig. 1. B.
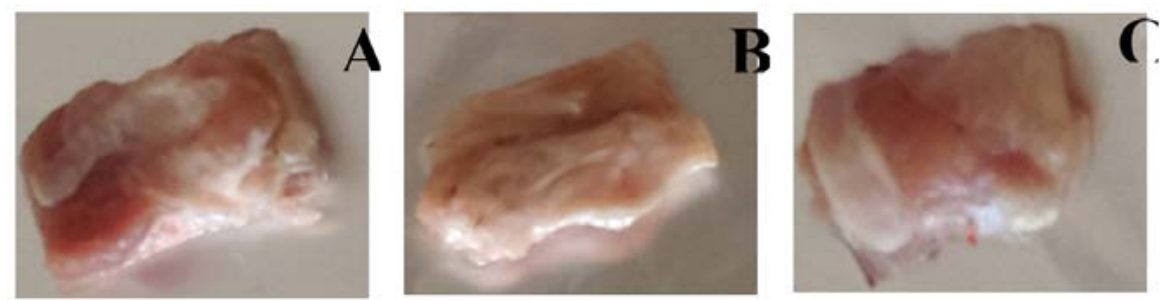

Fig. 1. C.
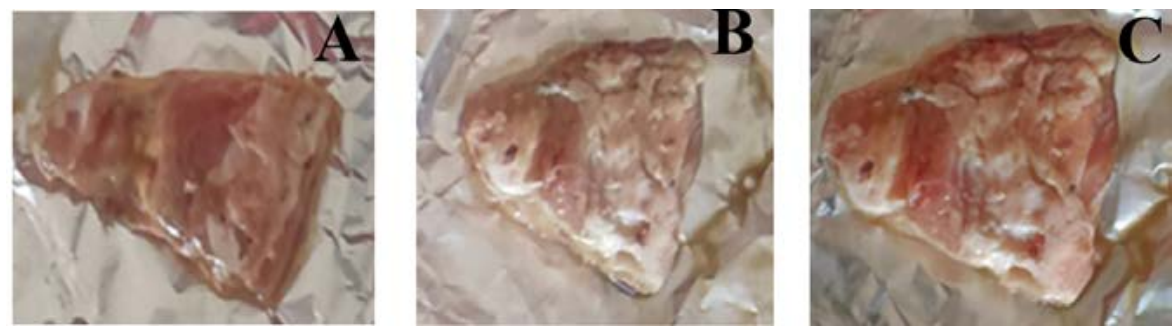

Fig. 1. D.

Fig.1. A $0^{\text {th }}$ of chiken meat sample, B. $4^{\text {th }}$ day of chiken meat sample, C. $0^{\text {th }}$ day of Mutton meat sample, $4^{\text {th }}$ day of Mutton meat sample. Note: A. Control, B. Treated with culture and C. Treated with phage 
the with $31.98 \times 10^{5}, 33.13 \times 10^{6}, 10.97, \times 10^{7}$, treated and phage test as appeared in the Table $39.82 \times 10^{5}, 31.15 \times 10^{6}, 30.76 \times 10^{7}, 19.12 \times 10^{5}$, 1.C, Fig. 2.2. At incubation of temperature $15-30^{\circ} \mathrm{C}$ $10.03 \times 10^{6}, 10.03 \times 10^{7}$ individually with control, after culmination of the fourth day the treated with

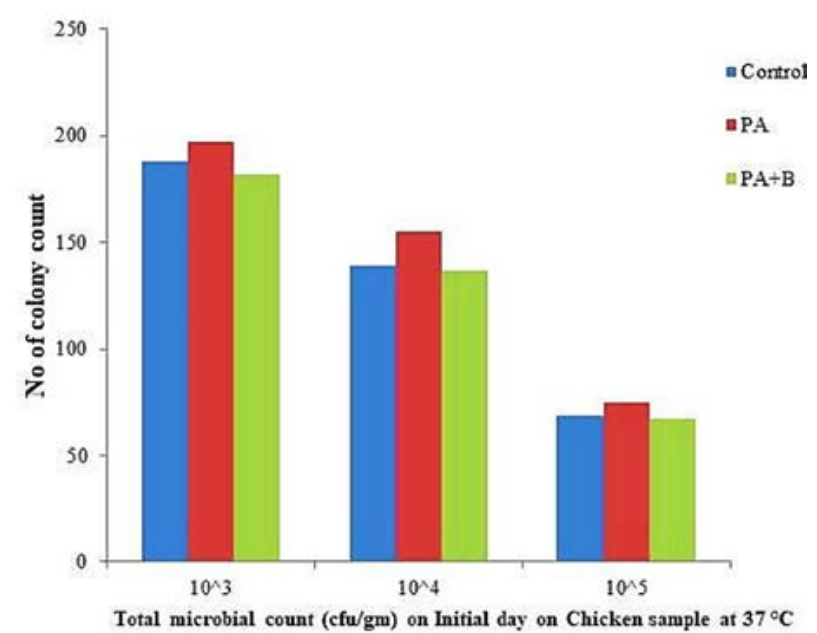

Fig. 2.1. Total Microbial count of chicken meat sample treated with strain and phage on Initial day

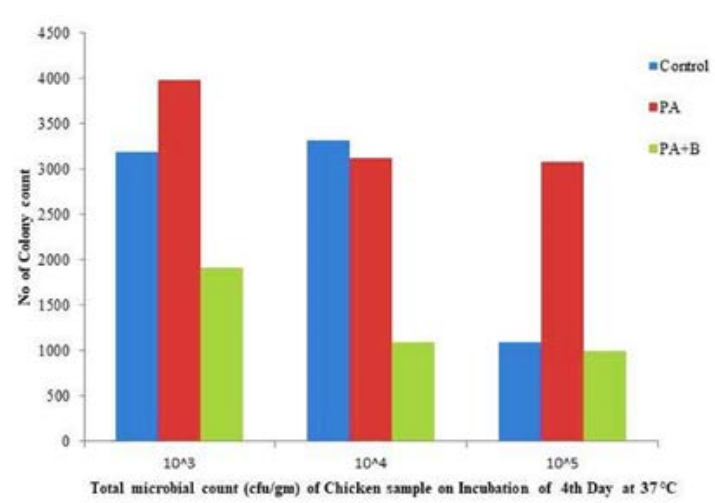

Fig. 2.2. Total microbial count of Chicken meat sample treated with strain and phage on $4^{\text {th }}$ day of Incubation at $37^{\circ} \mathrm{C}$

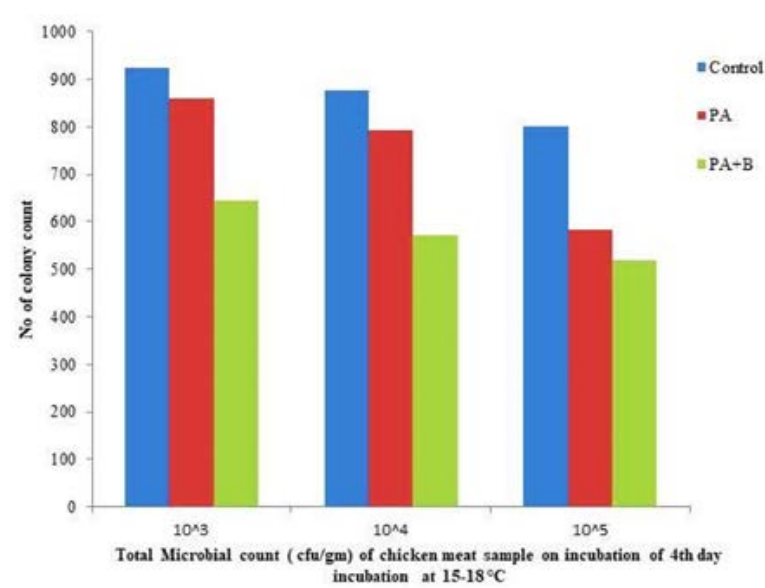

Fig. 2.3. Total microbial count of Chicken meat sample treated with strain and phage on $4^{\text {th }}$ day of Incubation at $15-18^{\circ} \mathrm{C}$.

Journal of Pure and Applied Microbiology 
phage as indicated the $6.43 \times 10^{5}, 5.73 \times 10^{6}, 5.19 \times 10^{7}$ as contrasted and strain and control individually as appeared in the Table 1.B, Fig. 2.3.

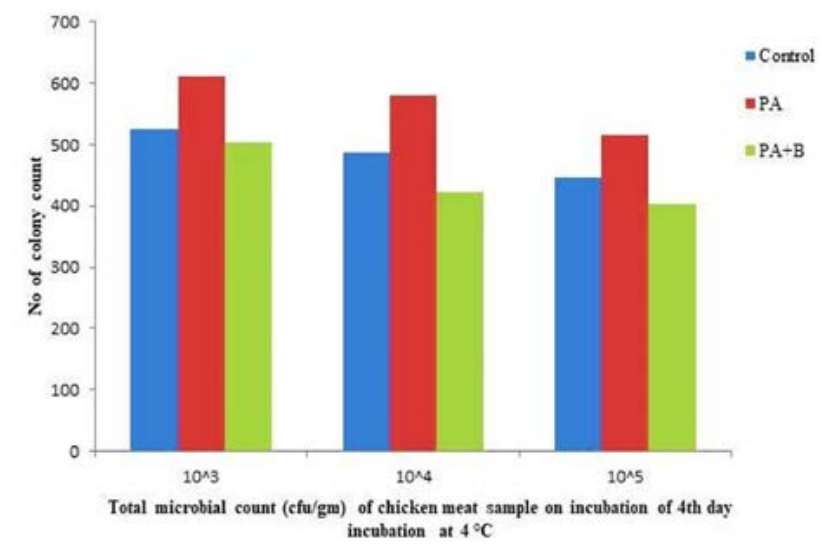

Fig. 2.4. Total microbial count of Chicken meat sample treated with strain and phage on $4^{\text {th }}$ day of Incubation at $4^{\circ} \mathrm{C}$.

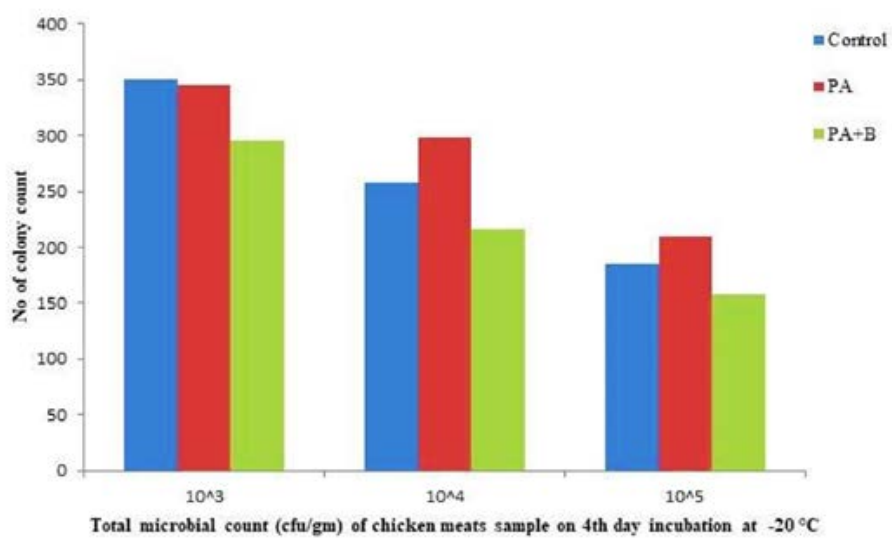

Fig. 2.5. Total microbial count of Chicken meat sample treated with strain and phage on $4^{\text {th }}$ day of Incubation at $-20^{\circ} \mathrm{C}$.

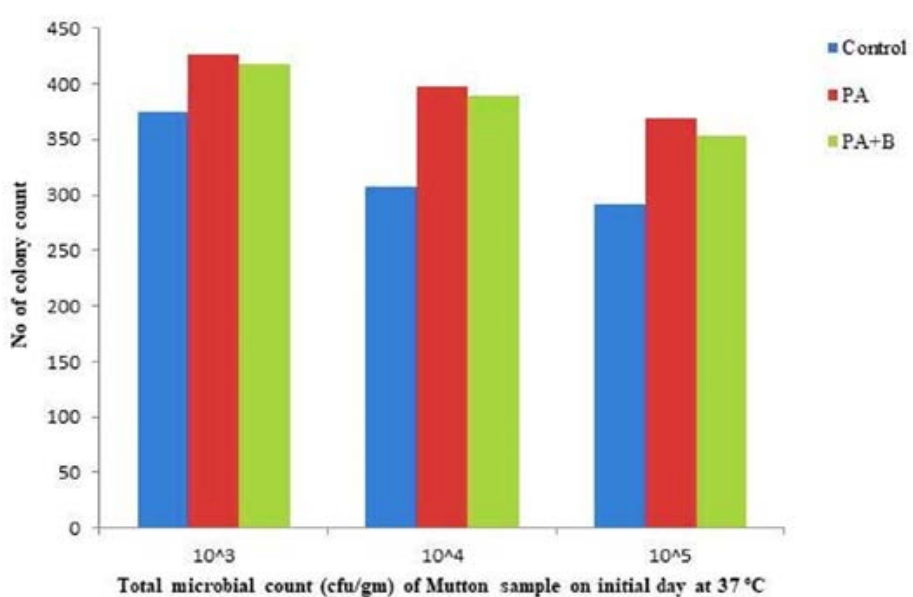

Fig. 2.6. Total microbial count of Mutton meat sample treated with strain and phage on Initial day 
and $2.95 \times 10^{5}, 2.16 \times 10^{6}, 1.58 \times 10^{7}$ respectively, compared with control and treated with culture as shown in the Table1. B, Fig. 2.4 and Fig. 2.5.

In case of the mutton sample the microbial observed as $3.75 \times 10^{5}, 3.08 \times 10^{6}$, and $2.91 \times 10^{7}$ on incubation of the initial day. The treated with culture has shown $4.27 \times 10^{5}, 3.98 \times 10^{6}, 3.69 \times 10^{7}$ and treated with phage as showed population of microbial growth as $4.18 \times 10^{5}, 3.89 \times 10^{6}, 3.53 \times 10^{7}$ respectively, as mentioned in the Table 1.C \& Fig. 2.6.

The growth of microbial population on $4^{\text {th }}$ day incubation at $37^{\circ} \mathrm{C}$ as showed the with $51.47 \times 10^{5}, 50.85 \times 10^{6}, 48.96 \times 10^{7}$, $50.98 \times 10^{5}, 49.82 \times 10^{6}, 47.36 \times 10^{7}, 21.15 \times 10^{5}$, $20.03 \times 10^{6}, 11.93 \times 10^{7}$ respectively with control, treated and phage sample as shown in the Table 1.C \& Fig. 2.7. At incubation $15-30^{\circ} \mathrm{C}$ after completion of the $4^{\text {th }}$ day the treated with phage as showed the $21.69 \times 10^{5}, 21 \times 10^{6}, 19.95 \times 10^{7}$ as compared with strain and control respectively as shown in the Table 1.C \& Fig. 2.8.

The elimination was observed at incubation of $4{ }^{\circ} \mathrm{C}$ and $20^{\circ} \mathrm{C}$ with microbial population of $13.87 \times 10^{5}, 12.76 \times 106,11.60 \times 10^{7}$ and $5.50 \times 10^{5}, 5.10 \times 10^{6}, 4.65 \times 10^{7}$ respectively; compared with control and treated with culture as shown in the Table 1.D, Fig. 2.9 and Fig. 2.10.

Physiological / Morphological characterization Banana

Physiological / Morphological characterization Fresh bananas were selected based on

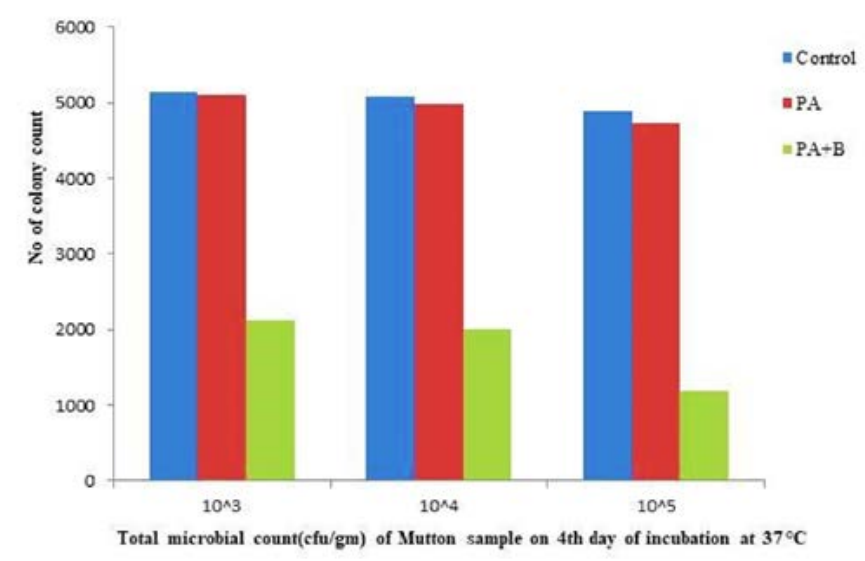

Fig. 2.7. Total microbial count of Mutton meat sample treated with strain and phage on $4^{\text {th }}$ day of Incubation at $37^{\circ} \mathrm{C}$.

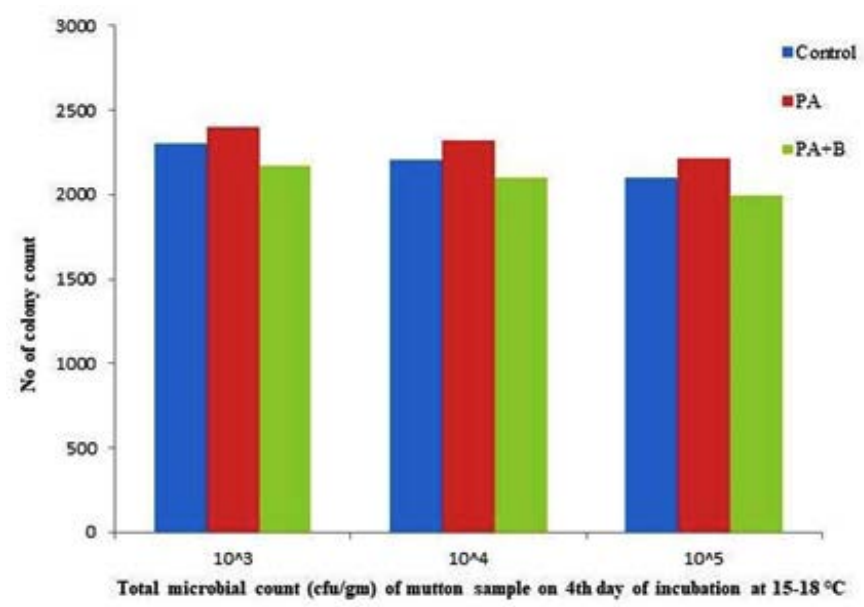

Fig. 2.8. Total microbial count of Mutton meat sample treated with strain and phage on $4^{\text {th }}$ day of Incubation at $15-18^{\circ} \mathrm{C}$

Journal of Pure and Applied Microbiology

2122

www.microbiologyjournal.org 
requirement and different preservatives are applied to the banana and observed for physiological and morphological changes were recorded as shown in Table 1.D, and changes of textures were shown in the Fig. 3.1 - 3.6 respectively up to incubation for 21 days. After peeling the bananas with its texture and morphology as shown in the Fig. 3.7 and Table 1.D.

\section{DISCUSSION}

In the present work we tried that our phage has showed elimination of foodborne $P$. aeruginosa infection and can be act as a biocontrol agent to overcome of the chemical synthesized agents. Phage therapy has effective intervention in controlling the foodborne pathogens in animals and plants before they enter in to the processing and product stage, even it has showed it can acts against different foodborne pathogens belongs to genera like $P$. aeruginosa, S. aureus, Salmonella, $E$. coli, Listeria, and Klebsiella (Lawrence et al., 2011; Hagens et al., 2010). These pathogens will come in contact during the food harvesting, slaughtering, processing, packaging and storage. Over the year the use antibiotic has been restricted due to risk of antibiotic resistant bacteria may invade in the human food chain and because adverse effects may lead to human antimicrobial treatment. The negative impact already knows of using physical methods on reduction of microbial load in raw foods and it implies on organoleptic properties of the products and reduces in their acceptability (Chibeu 2013). Thus, there is need in developing a novel strategies to eliminate or to reduce the bacterial pathogen load in foods and satisfying the consumer demand, with minimal use of low concentration of chemical preservatives. (Garcia et al., 2008).

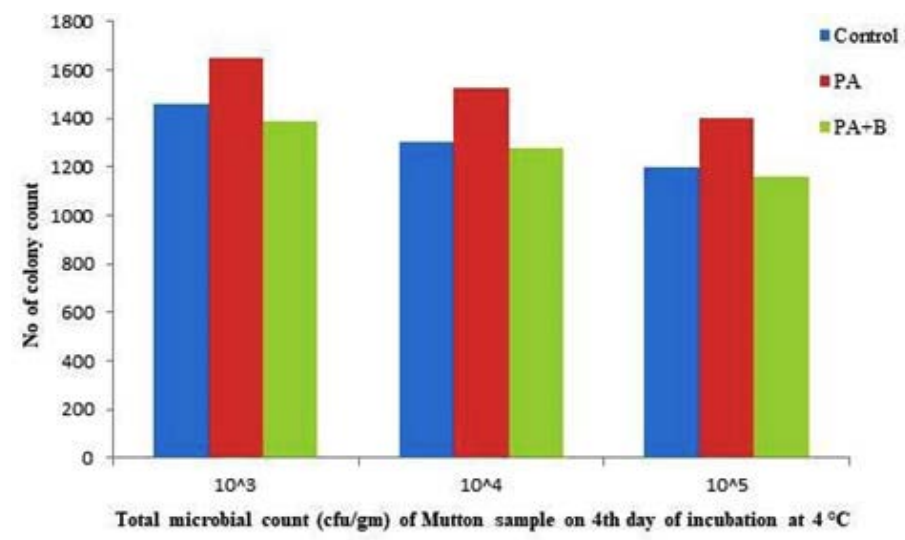

Fig. 2.9. Total microbial count of mutton meat sample treated with strain and phage on $4^{\text {th }}$ day of Incubation at $4{ }^{\circ} \mathrm{C}$

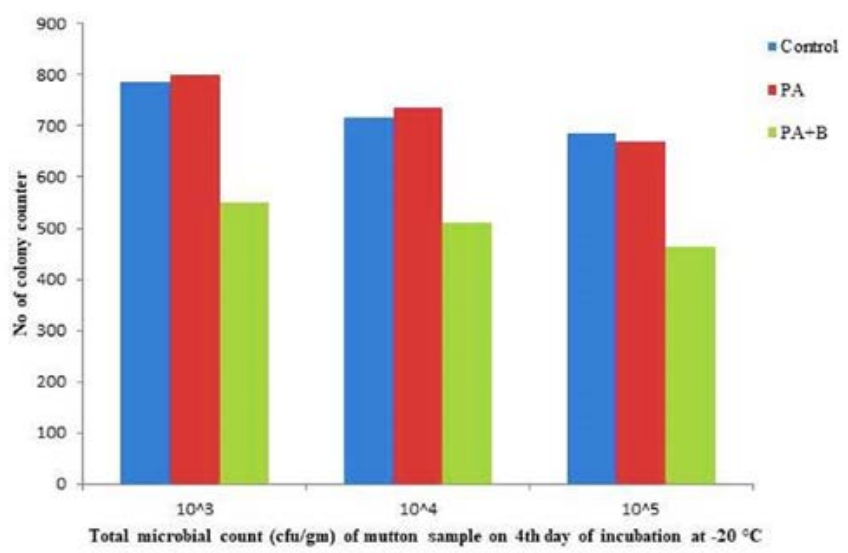

Fig. 2.10. Total microbial count of Mutton meat sample treated with strain and phage on $4^{\text {th }}$ day of incubation at $-20^{\circ} \mathrm{C}$ 
Bacteriophage acts a natural antimicrobial to reduce the bacterial pathogens in foods, food processing environments and a controlling agent. Phages can be used in postharvest intervention by applying on the surface of the foods, to improve food safety of the products. It also eliminates or reduces contamination with foodborne bacterial pathogens and makes the food to safe for the consumers. (Kok-Gan Chan et al., 2014). Phage as biocontrol mediators in controlling $C$. jejuni contamination on the surface of the meat and in turn it has reduced the infection within 24 hours. In combination with phage and chemical agents (i.e., dichloroisocyanurate, peroxyacetic acid,

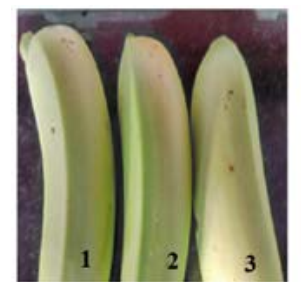

A

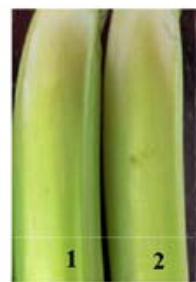

B

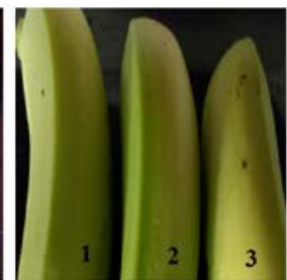

C

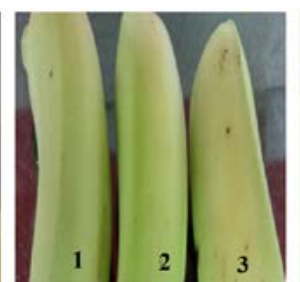

D

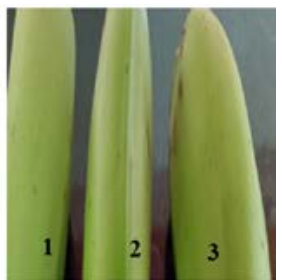

E

Fig.. 3.1. $0^{\text {th }}$ day of banana sample treated with different treatment A. Sodium alginate B. Starch C. Aloe vera D. Gelatin E. Glycerol

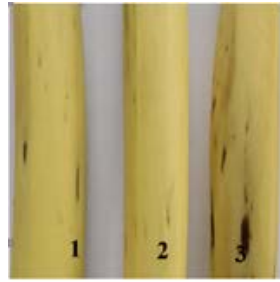

A

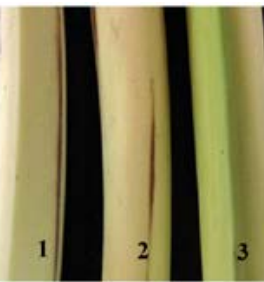

B

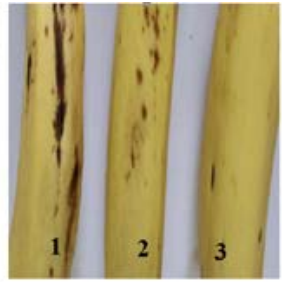

$\mathrm{C}$

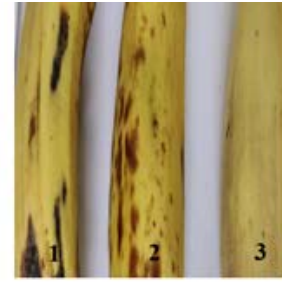

D

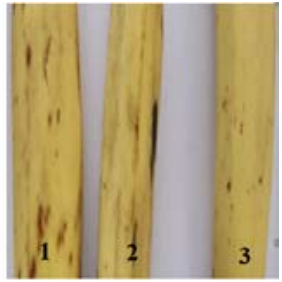

E

Fig. 3.2. $5^{\text {th }}$ day of banana sample treated with different treatment A. Sodium alginate B. Starch C. Aloe vera D. Gelatin E. Glycerol

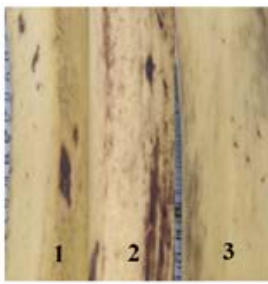

A

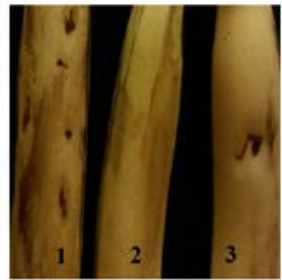

B

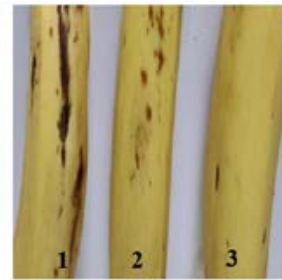

C

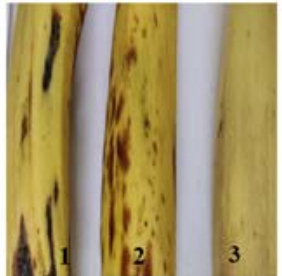

D

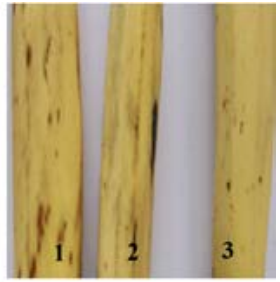

$\mathbf{E}$

Fig. 3.3. $9^{\text {th }}$ day of banana sample treated with different treatment A. Sodium alginate B. Starch C. Aloe vera D. Gelatin E. Glycerol

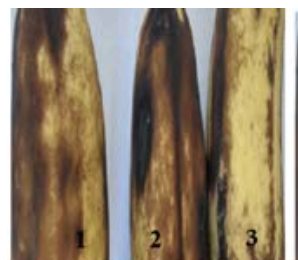

A

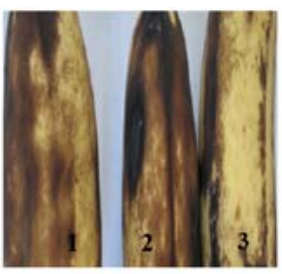

B

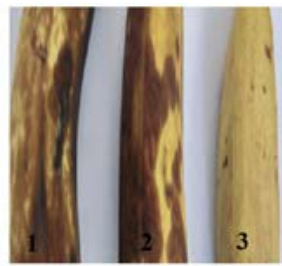

C

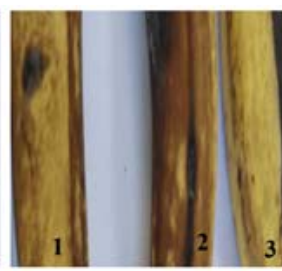

D

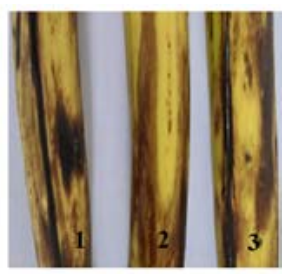

E

Fig. 3.4. 
lactic acid) as shown in reducing the caused by $S$. enteritidis on chicken skin. (Hungaro et al., 2013). Thus, both results conclude that bacteriophages can be used a 'bio-sanitizers'. Similarly, it can be used to control the bacterial infection caused by Pseudomonas species pathogen in poultry carcasses in industrial setting (Lorraine et al., 2014).

In present work $P$. aeruginosa specific bacteriophages were used as bio-controlling agent, applied as bio-control agents on the surface of foods (meat and banana), to eliminate or reduce the contamination of foods (meat and banana) and food product. It has shown there is reduction in the bacterial load within 24 hours of incubation. Use of Bacteriophage mixture for meat samples with different conditions $37^{\circ} \mathrm{C}, 15-18^{\circ} \mathrm{C}, 4^{\circ} \mathrm{C}$ and $-20^{\circ} \mathrm{C}$ incubation has reduced the bacterial load of $P$. aeruginosa in meat. Similar bacteriophage mixture is also applied to the banana samples along with different chemical agents (Sodium alginate, Starch, Gelatin, Glycerol, and Aloe Vera gel matrixes) and showed the reduction in the $P$. aeruginosa population in banana. Application implicate that bacteriophage can be used as alternative bio-sanitizers. For the improvement of food staple from bacterial, antibacterial method available now due to their extremely specificity against the particular bacterial bacteriophages and furthermore delicate of lytic bacteriophages in the improvement of food protection, since bacteriophages are available as universal in the

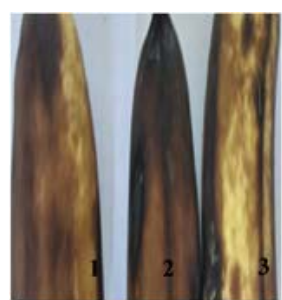

A

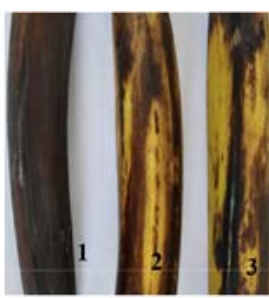

B

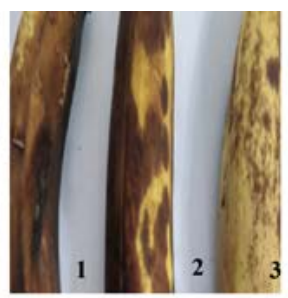

C

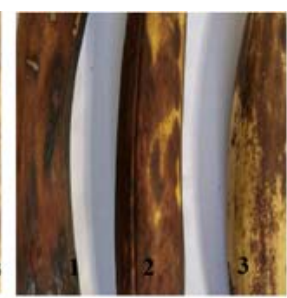

D

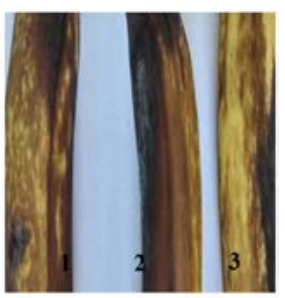

E

Fig. 3.5. $19^{\text {th }}$ day of banana sample treated with different treatment A. Sodium alginate B. Starch C. Aloe vera D. Gelatin E. Glycerol

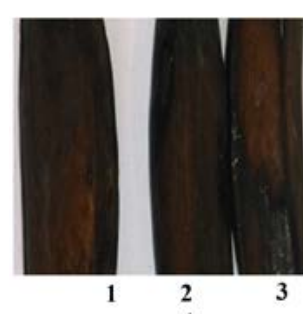

A

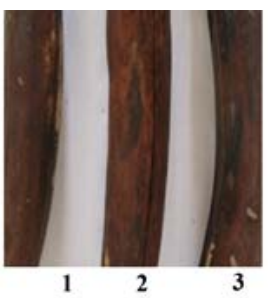

B

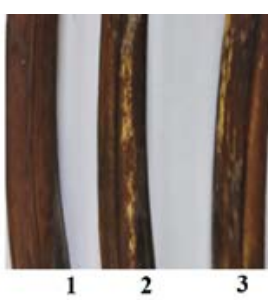

C
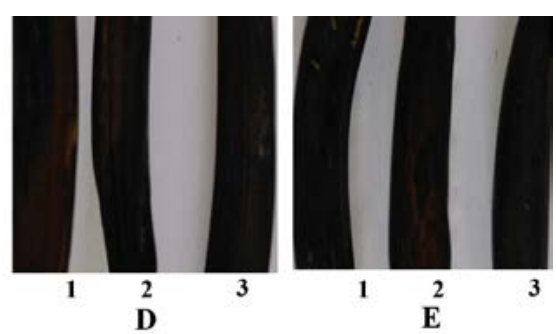

Fig. 3.6. $21^{\text {st }}$ day of banana sample treated with different treatment (before peeling) A. Sodium alginate B. Starch C. Aloe vera D. Gelatin E. Glycerol

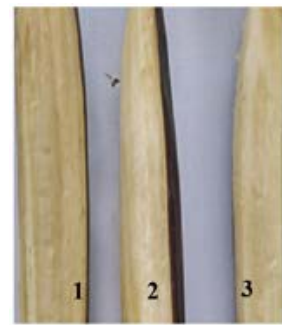

A

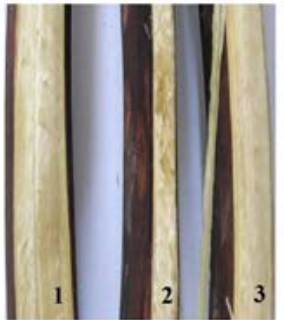

B

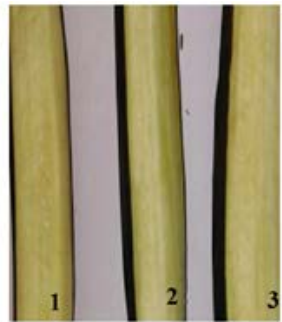

C

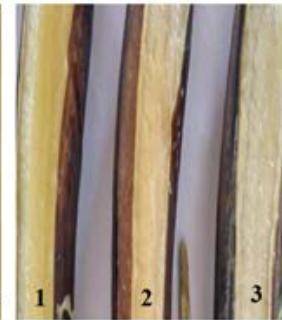

D

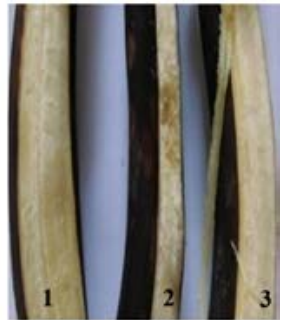

E

Fig. 3.7. After peeling Physiological / Morphological characterization of banana was observed and noted.A. Sodium alginate B. Starch C. Aloe vera D. Gelatin E. Glycerol 
environment demonstrating that human are exposed to them in daily basis (Skurnik et al., 2007).

Sodium alginate is a chemical preservative made of polysaccharide which is applied as edible coating materials on food. It maintains quality and shelf life of fresh products and also in the food industries (Mancin and Mchugh, 2000). It is extracted from the seaweed, the structure is made up of polymer of d-mannuronic acid (M) and I-gulucoronic acid (G) and it is salt of alginic acid in nature (Sime, 1990). It is available as a natural polymer and has the sole ability to bind multivalent cations; it inherent the gelling property. (Vennat et al., 1998).

Starch is known to be storage polysaccharide, it forms coherent, relatively strong, free-standing films in divergence to amylopectin films which are brittle and noncontinuous (Zobel, 1998). Transparent, carries very low oxygen permeability in dry condition when it's mixed with water- butanol solution to form the gelatinized amylase to cast oil impermeable films (Wolff et al., 1995). Presumably, films cast from ethanol- water dispersions of dimethyl sulfoxide pre-treated high amylase (71\%) starch retained low oxygen permeability even at high $\mathrm{RH}$ (Mark et al., 1990).

Gelatin commonly present in nature as constituent of skin, bone, and connective tissue and is obtained from hydrolysis of fibrous insoluble protein and collagen. It consists of high amino acids like glycine, proline and hydroxyproline. Gelatin also has a mixture of single and double unfolded chains of hydrophilic character (Dhall et al., 2013). The application of gelatin in pharmaceutical and food industries it is used as microencapsulation of ingredients and manufacture of tablet and capsule coatings. Like other edible films, gelatin coatings have shown potential as carriers of antioxidants (Muhammad et al., 2013).

Glycerol is chemically sugar alcohol. Food graded glycerol is used as a humectant (wetting agent), thickener, solvent, or sweetener to dairy product (cream), canned goods, confections, fondant, processed fruits, jams, energy bars and other foods. The glycerol which is extracted from the sources of animal or vegetable oil, corn syrup, petroleum is also used in a food product is usually not revealed on the food labels.
Aloe vera due to its moisturizing effect, anti-bacterial and anti-fungal properties it used as novel edible coating to extend the shelf life of fruits and vegetables. It has revealed that it prevents the loss of moisture, firmness, rate of respiration, maturation, oxidative browning and less proliferation of microorganisms. (Sonu et al., 2016).

Numerous bacteriophages exist on the fresh, fermented foodstuff, fresh poultry, meat and raw vegetables that have not been processed extensively. These boosts that generally human will consume enormous amounts of phage in day to day and therefore phages can be consumed as it is safe. (Carlton et al., 2005). Numerous experiments resulted that it is safe and can used as a bio-control agent. Even they reported that using high or low concentration phage dosage results any adverse effects. The current proofs suggest that the intake of phage with food is safe and it can be used as an additive for bio-preservation of foods (Kang et al., 2013). In present work application of bacteriophages directly on food surface without any damage to the foodstuff, animals and humans, it can be used as bio-preservatives for preserving the foods without any side effects.

The conclusion of the study, bacteriophages recognized has potential biotherapeutic agents. Bacteriophage therapy and phage-based detection system have an emphasis on demand due to increase in antibiotic treatment and for rapid detection of the pathogens in food. The bacterial pathogen receptor knowledge and colonization factors provide to target the bacteria to treat with phage. Phage analysis will give in identification of phage lacking integration machinery, which will facilitate safe and effective use of phages as bio control agents. The present research emphasis the recent advances in the research of phages that target food pathogens and promote their use in bio sanitation.

\section{ACKNOWLEDGMENTS}

We would like to express our heartfelt thanks to B.V.V. Sangha's Basaveshwar Engineering College (Autonomous), Department of Biotechnology, Bagalkot for provide platform to complete our research work. 


\section{CONFLICT OF INTEREST}

The authors declare that there is no conflict of interest.

\section{AUTHORS' CONTRIBUTION}

All authors list have made a substantial, direct and intellectual contribution to the work, and approved it for publication.

\section{FUNDING}

None.

\section{DATA AVAILABILITY}

All datasets generated or analyzed during this study are included in the manuscript.

\section{ETHICS STATEMENTS}

Not applicable.

\section{REFERENCES}

1. Ankita BPU, Umesh PS. Microbial Contamination of food available in sub metropolitan city Birgunj in Nepal and its effect on Human health. International Journal of Biosciences and Technology. 2012;5(15):82.87.

2. Brussow $\mathrm{H}$, Hendrix RW. Phage genomics: small is beautiful. Cell. 2002;108(1):13-16. doi: 10.1016/ S0092-8674(01)00637-7

3. Carlton RM, Noordman WH, Biswas B, Meester ED, Loessner MJ. Bacteriophage P100 for control of Listeria monocytogenes in foods: genome sequence, bioinformatics analysis, oral toxicity study and application. Regul Toxicol Pharm. 2005;43(3):301-312. doi: 10.1016/j.yrtph.2005.08.005

4. Ceyssens PJ, Lavigne, R. Bacteriophage of Pseudomonas. Future Microbiol., 2010;5(7):1041-1055. doi: 10.2217/ fmb.10.66

5. Chibeu A. Bacteriophages in food safety. Formatex. 2013;1041-1052.

6. Dhall RK. Advances in Edible Coatings for Fresh Fruits and Vegetables: A Review. Critical Reviews in Food Science and Nutrition.2013;53(5):435-450. doi: 10.1080/10408398.2010.541568

7. d'Herelle F. Surun microbe invisible antagonistic des bacilles dysenterique. C $R$ Acad Sci Paris. 1917;165:373-375.

8. Pires DP, Boas DV, Sillankorva S, Azeredo J. Phage Therapy: a step forward in the Treatment of Pseudomonas aeruginosa Infections. J Virol. 2015;89(15):7449-7456. doi: 10.1128/JVI.00385-15

9. Esteban JI, Oporto B, Aduriz G, Juste RA, Hurtado A. A survey of food borne pathogens in free- range poultry farms. Int J Food Microbiol. 2008;123(1):177-182. doi: 10.1016/j.ijfoodmicro.2007.12.012

10. Garcia P, Martinez B, Obeso JM, Rodriguez A. Bacteriophages and their application in food safety. J Appl Microbiol. 2008;47(6):479-485. doi: 10.1111/j.1472-765X.2008.02458.x
11. Hagens S, Loessner MJ. Bacteriophage for biocontrol of food borne pathogen: Calculations and considerations. Curr Pharm Biotechnol. 2010;11(1):5868. doi: 10.2174/138920110790725429

12. Healy B, Cooney S, O'Brien S, Iversen C, Whyte P, Nally J, Callanan, JJ. Fanning S. Cronobacter (Enterobacter Sakazakii): an opportunistic food borne pathogen. Foodborne Pathog Dis. 2010;7(4):339-350. doi: 10.1089/fpd.2009.0379

13. Hungaro MH, Santos MRC, Gouvea DM, Danatas VMC, de Oliveira Pinto CL. Use of bacteriophages to reduce Salmonella in chicken skin in comparison with chemical agents. Food Res Int. 2013;52(1):75-81. doi: 10.1016/j. foodres.2013.02.032

14. Jaewoo B, Kim Y-T, Sangryeol R, Lee J-H. Bio-control and Rapid Detection of Food-Borne Pathogens Using Bacteriophages and Endolysins. Front Microbiol. 2016;7(474):1-15. doi: 10.3389/fmicb.2016.00474

15. Jennifer $M$, Olivia $M$, Auliffe RPR, Douwe van $S$. Bacteriophages as biocontrol agents of food pathogens. Curr Opin Biotechnol. 2011;22(5):157-163. doi: 10.1016/j.copbio.2010.10.008

16. Kalkan S, Unal E, Erginkaya Z. Bio-control of Some FoodBorne Pathogenic Bacteria by Bacteriophage. Journal of Food Science and Engineering. 2011;1:237-244.

17. Kang HW, Kim JW, Jung TS, Woo GJ. A new biocontrol agent for Salmonella enteric, Serovar Enteritidis and Typhimurium in foods: characterization, application, sequence analysis and oral acute toxicity study. Applied Environmental Microbiology. 2013;79(6):1956-1968. doi: 10.1128/AEM.02793-12

18. Letchumanan V, Chan K-G, Pusparajah P, et al. Insights into bacteriophage application in controlling vibrio species. Front Microbiol. 2016; 7:1-10. doi: 10.3389/ fmicb.2016.01114

19. Lawrence D, Goodridge B B. Phage based biocontrol strategies to reduce foodborne pathogens in foods. Bacteriophage. 2011;1(3):130-137. doi: 10.4161/ bact.1.3.17629

20. Endersen L, O'Mahony J, Hill C, Ross RP, McAuliffe O, Coffey A. Phage Therapy in the Food Industry. Annual Review. Food Science Technology. 2014;5:327-49. doi: 10.1146/annurev-food-030713-092415

21. Mancini F, Mchugh TH. Fruit-alginate interactions in novel restructured products. Nahrung. 2000;44(3):152-157. doi: 10.1002/1521-3803(20000501)44:3<152::AIDFOOD152>3.0.CO;2-8

22. Mark AM, Roth WB, Mehltretter CL, Rist CE. Oxygen permeability of Amylomaize starch films. Food Technology. 1990;20:75-77.

23. McIntryre LJA, Hudson C, Billington $\mathrm{H}, \mathrm{W}$. Biocontrol of Food borne Bacteria: Past, Present and Future Strategies, Scientific Supplement August/ September, New Zealand. 2007;25-32.

24. Muhammad IK, Muhammad NA, Muhammad RT, Muhammad S. Application of edible coating for improving meat quality: A review. Pakistan Journal of Food Science. 2013;23(2):71-79.

25. Novik G, Savich V. Bacteriophages of Pseudomonas bacteria: application in medicine and agriculture. Formatex. 2015;295-304.

26. Sime WJ. Alginates, In Food gels, Ed., P. Harris. Elsevier 
Applied Science: London. 1990;53-58.

27. Skurnik M, Pajunen M, Kiljunen S. Biotechnological challenges of phage therapy. Biotechnological letter. 2007;29:995-1003. doi: 10.1007/s10529-007-9346-1

28. Sonu P, Bhawana M, Preeti G. Permeability of Aloe vera composite coatings and their effect on quality of peeled carrots. Current Science. 2016;111(12):20312035.

29. Twort FW. An investigation on the nature of ultramicroscopic viruses. Lancet. 1915;186(4814):12411243. doi: 10.1016/S0140-6736(01)20383-3
30. Vennat B, Lardy F, Arvouet-Grand A, Pourrat A. Comparative texturometric analysis of hydrogels based on cellulose derivatives, Carraghenate and alginates: Evaluation of adhesiveness. Drug Development and Industrial Pharmacy. 1998;24(1):27-35. doi: 10.3109/03639049809082349

31. Wolff IA, Davis HA, Cluskey JE, Gundrum LJ, Rist CE. Preparation of films from amylase. Industrial and Engineering Chemistry. 1995;43(4):915-919. doi: 10.1021/ie50496a039

32. Zobel HF. Molecules to granules: a comprehensive starch review. Starch-Starke. 1998;40:44-50. doi: 10.1002/star.19880400203 